\title{
Systems Perspectives on the Interaction Between Human and Technological Resources
}

\section{Toivonen-Noro, Marja Ireene}

SPRINGER-VERLAG SINGAPORE PTE LTD

2019

Toivonen-Noro , M I \& Kijima , K 2019 , Systems Perspectives on the Interaction Between Human and Technological Resources . in M Toivonen \& E Saari (eds), Human-Centered Digitalization and Services . Translational Systems Sciences, vol. 19 , SPRINGER-VERLAG SINGAPORE PTE LTD , Singapore , pp. 37-56 . https://doi.org/10.1007/978-981-13-7725-9_3

http://hdl.handle.net/10138/330609

https://doi.org/10.1007/978-981-13-7725-9_3

acceptedVersion

Downloaded from Helda, University of Helsinki institutional repository.

This is an electronic reprint of the original article.

This reprint may differ from the original in pagination and typographic detail.

Please cite the original version. 


\title{
Chapter 3
}

\section{Systems perspectives on the interaction between human and technological resources}

\author{
Marja Toivonen $^{1}$ and Kyoichi Kijima ${ }^{2}$
}

\begin{abstract}
Along with the development of digitalization, it has become apparent that focusing on technology is not enough but the crucial issue is how to link together technological and human resources. Systems thinking is needed to understand the interdependencies resulting from these linkages at different levels: in activity systems at the micro level, in networks and ecosystems at the meso level, and in the institutional set-up that supports and regulates the development at the macro level. In this chapter, we analyze these interdependencies in more detail. As a starting point for these analyses, we point out basic principles of systems thinking and present central benefits of the application of this thinking. We also consider the highly dynamic nature of the development of digitalization: we examine how the systems perspective can be applied in the conditions of change. A central message throughout is the view that the value of a specific resource depends on its relation to other resources.
\end{abstract}

Keywords: digitalization, human resources, activity systems, networks, ecosystems, societal regulation

\section{$1 \quad$ Introduction}

Since the end of the 1980s, information and communication technologies (ICT) have been a prominent technology driving the development of the modern economy. During the first 'wave' of the ICT breakthrough, there was already a lively discussion among academic scholars and policy makers about the nature of the ongoing change. A central issue in this discussion was whether the development should be analyzed primarily in terms of technological innovation or whether the human and social aspects of ICT should also be in the spotlight.

'A technologist view' dominated the early discussion (Gallouj, 2002), but there were champions who advocated a broader perspective. They highlighted that in the adoption of technological novelties, human activities play an important role: novelties are re-invented in use, they are supplemented with context-specific meanings, and the related social relationships are restructured (Tuomi, 2002). Re-invention is due to the fact that new technologies are not completed and unchangeable artefacts, but very often need modifications. They are also actively interpreted and appropriated by the users and have different meanings for different user groups. Furthermore, social practices change together with the incorporation of new technologies (ibid.).

\footnotetext{
${ }^{1}$ Marja Toivonen

Helsinki University

marja.toivonen-noro@helsinki.fi

${ }^{2}$ Kyoichi Kijima

Daito Bunka University

kijima@ic.daito.ac.jp
} 
The discussion between the proponents of the 'technologist view' and the representatives of the broader perspective was crystallized in the main scholarly concept that was applied to characterize the new ICT era. The concept of 'information economy (or information society)', which was first adopted, focused on the new ways to handle, compile, transfer and store information. It was soon supplemented or even replaced with the concept 'knowledge economy (or knowledge society)' (Antonelli, 1998; Lundvall, 1992). While appreciating information infrastructures as a necessary precondition, the proponents of this concept emphasized that knowledge is more than information: its core contents are interpretation and application. Along with the advancements of ICT, the real issue is how to find the essentials, i.e. how, where and when to dip into information flows. Need for competences linked with locating and selecting contextually relevant information and using it in efficient ways notably grows. (ibid.)

The rise of the Internet in the 1990s and at the beginning of the new millennium induced again a new emphasis in the main concept used to summarize the most important megatrends in society. The rapid rate of change was brought to the fore and was argued to require capability to produce new knowledge continuously and quickly. Thus, the process of learning was highlighted instead of the stock of knowledge, i.e. the knowledge possessed by agents and organizations at a certain point of time. The concept of 'learning economy (or learning society)' was suggested as a concept that best captures the novel aspects in the societal development (Lundvall, 1999). The importance of practical forms of learning - 'learning-by-doing' and 'learning-by-using' - were pointed out besides conscious search. Correspondingly, 'knowinghow', based on practical skills, was considered as necessary as knowledge of facts and reasons ('knowing-what' and 'knowing-why') (Lundvall and Johnson, 1994).

'Learning-by-interacting' was identified as a new form of learning that specifically characterizes the Internet era (Johnson, 1992; Lundvall, 1992). It refers to 'a network economy (or network society)' (Castells, 1996) - the fourth concept that was adopted to describe the essentials of the ongoing societal development. Here, the basic idea is that knowing how to do things in isolation is not the decisive type of knowledge any more. The creation of new knowledge in the Internet era is a collective undertaking that involves a number of actors with different skills and competences (Kash and Rycroft 1994). ICT provides an important infrastructure for networking practices, but these practices do not develop on the basis of technology only. New insights concerning collaborative models are crucial and function as a further incentive to improvements of technology (Castells, 1996). To point out the specificities of knowledge needed in interactive processes and cooperation, researchers have suggested additional types of knowledge: 'knowing-who', 'knowing-when' and 'knowing-where' (Lundvall and Johnson, 1994).

The broad view of technology is even more topical today when digitalization means a deeper change than the earlier advancements of ICT. The current development includes factors that easily lead to technological bias if attention is not payed to the human and social aspects and impacts. Along with the new digital systems, automation and robotics, the replacement of some intellectual activities has become a reality. An especially noteworthy phenomenon in the new phase of the Internet economy is the interaction of digital equipment without human interference. The accumulation of data is no longer limited to human creation, but different devices and sensors collect, store and transfer data automatically, reflecting the phenomenon of the 'internet of things' (Haller et al., 2009). The concept of 'big data' refers to the huge mass of data emerging in this way. Consequently, there are increasing amount of data, increasing speed of data transfer, and increasing variety of data sources (Boyd and Crawford, 2012; Gunther et al., 2017). A major increase in dynamism is a fundamental constant in our world the new normality of and in organizations (Farjoun, 2010).

Digitalization is today an essential part of all kinds of social and economic activities and the everyday life of citizens. However, the related new opportunities will not be realized 
without human activities: interpretation is still a necessity and is linked to the contextual nature of relevant knowledge. Digitalization does not make human activities less important but highlights a broad, knowledge-based view on technology and new ways of human-technology interaction (Wieland et al., 2016). Digitalization means - not only automation - but also networking, mobility, socio-structural shifts, and globalization (Stein, 2015). It is an opportunity because of novel solutions to various problems, but it is also a threat because novelties mean uncertainty. These uncertainties are strengthened by the systemic features of human and social activities: the abundance of interconnected elements and feedback loops, the unexpected non-linear behavior, non-transparent cause-effect relationships, and unpredictable side effects and secondary effects (ibid.).

In this chapter, we discuss the human and social side of digitalization in more detail, taking a systemic view as our starting point. First, we point out basic principles of systems thinking and present some central benefits of the application of this thinking. Thereafter, we examine systemic interdependencies and digitalization at different levels: human-technology interaction in activity systems at the micro level, networks and ecosystems at the meso level, and the institutional set-up that regulates the development at the macro level. In addition to the emphasis on systems thinking, we highlight the role of resource integration: the idea that the value of a specific resource depends on the context: on its relation to other resources (Vargo and Lusch, 2011). Before concluding remarks, we examine how the systems perspective can be applied in the conditions of change. In this way, we take into account the highly dynamic nature of the development of digitalization.

\section{$2 \quad$ Principles and benefits of systems thinking}

Now we introduce basic principles of systems thinking and illustrate why it is relevant to adopt systems thinking to investigate interaction between humans and technological resources. According to a standard dictionary, a system is defined as 'a set or an arrangement of elements so related or connected as to form a unity or organic whole' (Webster's New World Dictionary). Though different dictionaries may contain different variations of this particular formulation, this definition captures the essence of a system and is helpful to provide a starting point to arguing the idea of systems thinking.

Systems thinking is a holistic approach for describing and understanding systems, predicting their behaviors, and devising modifications to them in order to produce desired effects by focusing on their systemic properties, or 'systemicity'. It contrasts with reductionist approach, which studies objects by breaking them down into their separate elements. We can apply systems thinking, in principle, not only to social science but also to a wide range of other disciplines including medical, environmental, political, economic, and engineering studies.

System thinking, among others, tries to figure out how a system's elements/parts interrelate each other and how systems work over time and within the context of larger systems. Indeed, interaction between parts is the key systemic property that systems thinking focuses on. Interaction among parts is assumed at least as important as the parts themselves: the fact that systems scientists call interaction and elements/parts systemhood and thinghood, respectively, (Klir, 2001) clearly shows what importance they put on interaction.

Systems have behavior resulting from the interaction of element behaviors. The term 'synergy' is used to describe the essentials of the well-known idea that 'the whole is greater than the sum of the parts'. It is also possible to have 'negative synergy' where the whole is less than the sum of the parts.

It might be appropriate to identify a system as complex if it contains a sufficient number of elements and if these elements are heavily interconnected with each other. Complexity 
frequently takes the form of hierarchies (Simon, 1962). Hierarchical systems have some common properties independent of their specific content, and they will evolve far more quickly than non-hierarchical systems of comparable size (Simon, 1996). The term 'emergence' refers to behaviors generated across hierarchies of a complex system.

System's dynamic mechanism, which systems thinking is interested in, is explained in terms of feedback mechanism. Feedback is classified into two types. Negative feedback is for maintaining the system state against a set of objectives or levels, while positive feedback forces growth or contraction to new levels. One of the main issues here is the balance between stability and speed of response. Negative feedback is essential for adaptation of the system; by adaptive transition a system tries to change itself or its environment to achieve stability. Positive feedback is taken as a source of evolution and phase transition.

By adopting systems thinking we can highlight such systemic properties of socio-technical systems as interaction, complexity, hierarchy and feedback mechanism when investigating interaction between human and technological resources.

A socio-technical system is obviously an extremely complex system where various elements including human and technological resources interrelate with each other. It forms control hierarchies. Systems within a hierarchy of society show adaptive transitions as well as phase transitions (Kijima, K. et al., 2016) (See Figure 1). Systems at a higher level have some ownership of control and regulation over those at lower levels to form 'preferred patterns' which can be used to the enhanced stability of interacting systems hierarchies (Hitchins, D., 2009). At the same time, systems at lower levels generate system's patterns at higher levels. This kind of regulation and generation across the levels is called 'micro-macro loop'. It is useful to employ the micro-macro loop as a 'unit component' in a recursive way for analyzing practice of interaction between human and technological resources.

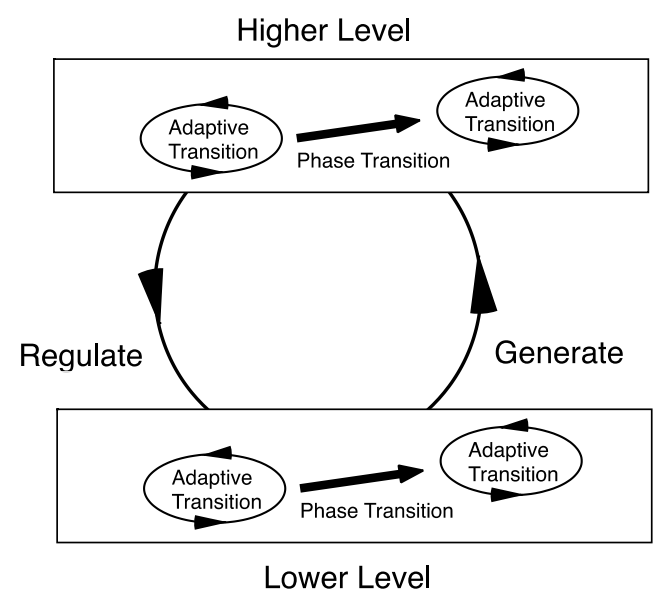

Figure 1. Micro-macro loop

\section{Digitalization as a driver for interaction between human and technological resources}

As noted in the introduction, digitalization influences human activities in multiple ways. These influences can be examined both as general trends and as specific changes in different social spheres and economic sectors. In the following, we combine these approaches: we present some 
general frameworks and models to analyze the impacts of digitalization at various levels and examine developments going on in private life, workplaces, and in various societal sectors (health care, education etc.).

\subsection{Human-technology interaction and the concept of activity system}

Digitalization effects on the role of the technology user in various physical environments and social conditions. Its impacts have often been argued to be emancipatory, increasing the autonomy and freedom of users. On the other hand, the use of digital technologies requires many kinds of capabilities: on-line reactions, rapid learning, and flexibility in relation to continuous change. These capabilities are linked to ICT literacy - the ability to access, analyze, and produce communication in a variety of digital forms - which is not self-evident among different user groups (Tyner, 2014). Consequently, concern about digital divide, i.e. unequal access and usage of the digital sphere, has been expressed. It is seen to prevent the full realization of the democratizing tendency enabled by digitalization (Ragnedda and Muschert, 2013). Along with the spread of Internet, the focus of the discussion about inequalities has moved from the mere 'have not' issue to the lack of digital proficiencies that creates 'second level digital divide' (van Dijk, 2013).

A central feature of the current digital era is marketizing. Permeating digital technologies engage increasing numbers of children, young people and adults as consumers. There is a pressure on people of all ages to make sense of and choices about how to navigate the complex possibilities facing them. Connectivity around the clock, with a parallel existence in virtual space, is seamlessly integrated with actual lives. People have to be skillful collaborators, navigating digital spheres with ease, being capable to generate and manipulate various contents, creating social networks and experimenting virtually with versions of their 'social face' (Craft, 2012). The strengthening role as consumers has aroused critique towards the digital revolution in the case of children and youth, in particular. There are two competing discourses: young people are seen as vulnerable and at risk; or they are described as capable and potent. The latter view embraces digitalization as exciting and enabling - fostering co-creation that nurtures plurality, participation and possibilities (Livingstone et al., 2011).

The blurring of the distinction between reality and virtuality characterizes working life, too. In this context, an important characteristic is also the blurring of the distinction between human and machine (Floridi, 2015). Factory objects are increasingly equipped with integrated processing and communication capabilities: various sensors, software and network connectivity opportunities enable machine-to-machine (M2M) communication. As machines, equipment and component parts become autonomous and self-organizing, they become an active part of business processes (Brettel et al., 2014). This development has far-reaching consequences for the interplay of humans and technology in terms of control, for instance. Both problems and demands in the factory space will change, and even very complex manufacturing scenarios become manageable. In contrast to the earlier approaches (especially those in the 1980s), the current evolvement of digitalization is not gravitating towards workerless production facilities. On the contrary, the aim is to integrate employees into the production structure in such a way that their individual skills and talents can be fully realized (Gorecky et al., 2014).

The nature of work is radically changing also in the services provided for the welfare of citizens. Health care, in particular, is an area that has experienced a considerable transformation as a result of digitalization. A central element is a change in the roles of patients and professionals: patients are encouraged to take up new digital technologies to carry out selfmonitoring and self-care. This patient engagement is usually fostered as part of the so-called integrated care programs whose purpose is to streamline care processes, improve the access to 
services, and diminish financial problems that characterize the health sector in most developed countries. In addition to active utilization of digital options, these programs include patient support and education, structured clinical follow-up and case management, and multidisciplinary care teams (O'Connor et al., 2016). While the aims are reasonable, the transformation is not always welcomed by patients; the burden of self-care provokes emotions and resistances. It is also possible that the digital solutions do not substantially diminish the total workload of professionals because digitalization multiplies the amount of data and consequently increases 'invisible work' linked to handling of this data (Lupton, 2013).

Learning is a core topic in the discussion on digitalization. Several concepts have been adopted to capture the new forms of learning: the concepts of e-learning, mobile learning, and ubiquitous learning describe the broadening scope of opportunities (Siemens, 2005). Humantechnology relationship in the digital context has also evoked multiple theoretical analyses, ranging from the application of the classical learning theories (e.g. Dewey, 1938) to new approaches (e.g. the theory of connectivism suggested by Siemens, 2014).

One popular approach is Activity Theory. Its core is the concept of activity system, defined as an interrelated set of elements, including individuals, objects, community, tools, rules and division of labor (Engeström, 1987, 2016). Activity refers to an interaction of the individual (subject) with objects; community constitutes a third node in the system. Three means mediate the contents of activity: tools for the subject-object interaction, rules for the subject-community interaction, and a division of labor for the community-object interaction. Thus, activity is systemic in nature, spanning an individual action and the collective interaction. Activity results in transformation of the object and of the knowledge and skills of the subject. Tools both constrain and support the learners in this transformation. Applied to the present framework (see Figure 2), digital tools facilitate the user to access information via human-technology interaction in a specific technological and community context that includes specific communication channels and protocols (Sharples et al., 2007).

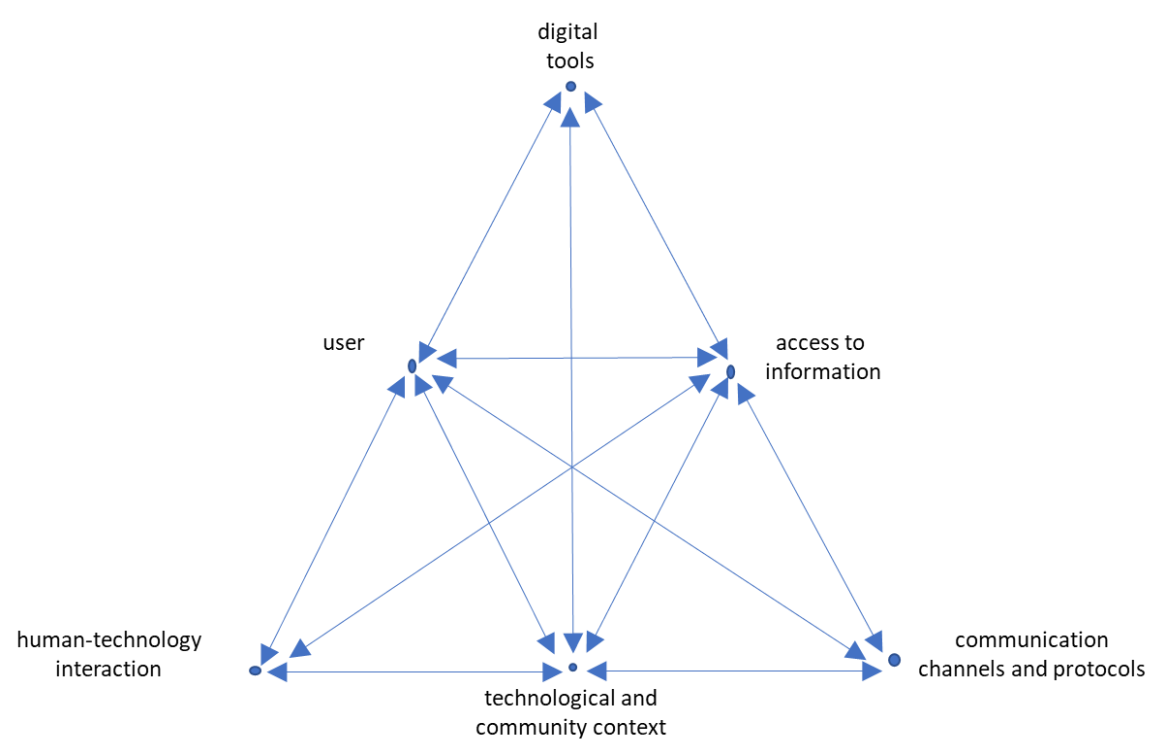

Figure 2: Activity system in the digital context (modified from Sharples et al., 2007)

In Activity Theory, learning is seen to be a collective, transformative process that takes place within an activity system that evolves over lengthy periods of socio-historical time (Engeström 1997, 2016). Digitalization means a shift from the primacy of stand-alone things and properties 
to the primacy of processes and interactions (Floridi, 2015). This characteristic of digitalization is well captured by Activity Theory, in which systems thinking and the idea of the integration of various resources are central (Mele and Russo-Spena, 2018). Even though this theory is a learning theory in the first place, it also enables a more general analysis of the micro level interactions between human beings and technology.

\subsection{Interaction in networks and ecosystems}

A central consequence of digitalization is the growing importance of networking. During the first 'wave' of the ICT breakthrough, 'a network economy' was already suggested as a concept that characterized the new era. Castells (1996) argued that the advancement of ICT fosters the emergence of a networked enterprise as the organizational form that answers the challenge of increasingly uncertain and unpredictable environments. According to him, a strength of networks lies in the shift from vertical bureaucracies to horizontal cooperation enabled by the use of ICT that connects dispersed organizational nodes. Individual members are dependent on the entirety, but they are also independent because they can be part of several other networks. An important aspect of networking is its relationship to innovation: a network organization combines the advantages of a bureaucratic organization with a structure that supports innovation (ibid.).

More recent discussion has supplemented these views, aiming at a better understanding of the continuous interaction and behavior of interconnected organizations (Ghisi and Martinelli, 2006). Business networks are a network type that has aroused notable interest. Researchers have emphasized that digital technologies are fundamentally transforming business strategies, business processes, firms' capabilities, products and services, and key interfirm relationships (Bharadwaj et al., 2013). The paradigm of atomistic actors competing against each other in an impersonal marketplace is becoming less adequate in a world in which firms are embedded in networks of social, professional, and exchange relationships with other economic actors (Gulati, et.al, 2000). As economic activity is changing from stand-alone to interconnected economic agents, there are increasingly - not only networks of organizations - but also network organizations. They are characterized by reciprocal and stable interorganizational ties, which are strategically important to participating firms. Multiplicity and density of ties are typical in a strategic network organization (ibid.).

In addition to collaboration between companies and organizations, digitalization fosters collaboration between organizations and consumers (Bharadwaj et al., 2013). An example is crowdsourcing, which is a collaboration model enabled by people-centric web technologies to solve individual, organizational, and societal problems using a dynamically formed crowd of interested people who respond to an open call for participation (Pedersen et al., 2013). The emergence of the internet and social media has significantly lowered the cost of involving masses of digitally connected consumers via virtual platforms. Crowdsourcing provides a grassroots perspective on how technological facilitation alters the realm of collective innovation: social interactions trigger new interpretations and new discoveries that individual actors' thinking alone could not have generated (Hargadon and Bechky, 2006).

An important step in the study on networks has been the introduction of the concept of ecosystem (Iansiti and Levien, 2004). This concept provides a way to enrich the analysis of networks by considering the organization as an interconnected part of its larger environment, and by emphasizing both the role of the individual organization and the collective 'health' of the system (ibid.). A crucial aspect that the concept of ecosystem brings to the study on networks is self-adjustment. Ecosystems are not just aggregations of relationships, but dynamic 
systems that are simultaneously functioning and reconfiguring themselves. Technology and innovation drive system evolution and performance (Lusch et al., 2010).

While the concept of ecosystem has been welcomed as an inspiring concept, it has turned out to be difficult to specify the differences between networks and ecosystems. Some researchers have noted that it is most interesting and useful to use the business ecosystem concept as a perspective to understand business networks, rather than as a new organizational form (Anggraeni et al, 2007). In addition, supplementing the views on business networks and ecosystems with other theories has been considered important. Social network theory and complex adaptive systems theory have been suggested as idea sources, in particular (ibid.).

Social network theory is of old origin: its first antecedents can be traced back to the 1940s and it is recognized as a coherent theory since the 1970s. Central topics of inquiry have been the quality and quantity of relational ties, the structural position of individual actors in a network, and the overall network properties (e.g. density, centralization, and modularity). An important contribution of social network theory is its broad scope; it includes actors both inside and outside the business world and also takes into account actors with indirect roles. Attention is payed to industries producing complementary products, outsourcing companies, competitors, regulatory agencies, financial institutes, research institutes, media and universities (Anggraeni et al., 2007). Social network theorists have also emphasized the versatility of the forms of networks and ecosystems. Besides strategic and stable forms, there are loosely coupled spatial and temporal structures and soft contracts. Weak interpersonal ties characterize this 'loose coupling' and can play an important role in the diffusion of ideas and information (Granovetter, 1973). With the ascendance of digitalization, spontaneity of sensing and responding increases and makes loose coupling all the more general (Lusch et al., 2010).

The theory on complex adaptive systems adds to the understanding of networks and ecosystems by emphasizing co-evolutionary processes and non-linear changes. A co-evolution process develops between the networks of localized and trans-local knowledge based on digital information exchange. Networks gradually evolve from random collections of agents to more structured communities with a reciprocal structure. Adaptation and survival are the hallmarks of this process (Gundlach, 2006). The network interacts and coevolves with its environment, which creates dynamics because there is feedback in terms of cooperation and competition. As complex systems, networks show non-linear behavior, stemming from the interaction of loosely coupled agents. Small changes can lead to different future paths in the form of structures, patterns and properties. In other words, the network structure and dynamics are emergent phenomena as a result of the self-organizing characteristics of a complex system, in which agents simultaneously and in parallel react on the changes (Choi et.al, 2001).

A recent approach applying the views on complex adaptive systems is service-dominant logic (S-D logic) (Vargo and Lusch, 2004, 2018). It has brought to the fore the role of value cocreation as a central economic activity. According to S-D logic, (use) value is always cocreated between the producer and the beneficiary (user) via the integration of resources from different sources. The usefulness of any particular resource from one source is moderated by the availability of other resources from other sources, the removal of resistances to resource utilization, and the actors' ability to integrate them (Lusch et al., 2010). It is also important to note that value co-creation always takes place in a specific context, formed by a set of unique actors with unique reciprocal links among them. Complexity emerges because links between two actors affect other actors and links throughout the context and vice versa. Thus, it is possible that hundreds of actors and links constitute one specific context (Chandler and Vargo, 2011). Further, the context is deeply social in nature: it is shaped by social forces and reproduced in social structures (Edvardsson et al., 2011). 


\subsection{Society-level issues of digitalization}

Besides the pervasive effects on human-technology interaction and organizational collaboration, digitalization transforms industry structures and contemporary society as a whole (Brynjolfsson and McAfee, 2014). Parallel with the new micro-level practices in workplaces and everyday life, there emerges macro-level societal issues that call for policy actions to seize the new opportunities for wealth creation and to defend society against the possible threats. The issues included are multiple and handling them in this context can be only exemplary. We point out three topics: the change of the nature of skills and employment, the concern on privacy and ethics, and the paradigmatic change in the public sector.

Digital technologies increasingly complement workers in complex problem-solving tasks while replacing humans performing rule-based manual labor. Recent developments suggest that even a wider range of jobs may become obsolete as pattern recognition capabilities are incorporated in robotic innovations (Brynjolfsson and McAfee, 2014). On the other hand, researchers have noticed that, throughout history, technological advances have created more new jobs than they have displaced. The emergence of totally new occupations has been particularly important. It is often neglected in pessimistic scenarios that typically focus on changes in existing occupations. However, there is constant need to update the skill set of workers to keep up with the evolving division of tasks between machines and humans (Mokyr et a., 2015).

Privacy and control are another major area of policy concern. While the protecting of sensitive information via anonymization, purpose limitation, individual rights etc. has considerably developed, new threats have emerged due to the continuously increasing collection of data from day-to-day activities of people. Smart things allow for ubiquitous data gathering, and Big Data Analytics can deal massive volumes of unstructured, structured and semi-structured content (Soria-Comas and Domingo-Ferrer, 2016). Social and ethical issues associated with the exploitation of digital technologies are highly topical, and thoughtful regulation of the use of these technologies is necessary. There is a tension between businesses and decision makers - that increasingly profile customers and personalize products and services - and individuals, who are 'walking data generators' but often unaware of how these data are being used, and by whom and with what consequences (McAfee and Brynjolfsson, 2012, 5).

In the public sector, digitalization both enables and requires a paradigmatic change towards citizen-centric operations. Whereas IT systems in the earlier stages mainly affected back-office processes, they now condition in important ways the whole terms of relations between government agencies and civil society (Dunleavy et al., 2006). The dominant forms of management - bureaucracy and market-imitating New Public Management (NPM) - have turned to be inefficient in this situation (Hartley, 2005). In the ongoing renewals of the public sector, the aim is to create a radically less complex institutional landscape, engineered for simplicity and automaticity in routine operations and for agility and responsiveness in service delivery and government's monitoring of the risk environment. Visibility of organizational operations both to the personnel and to citizens is highlighted, and reliance on citizens' own capabilities plays a central role. Fewer and broader public agencies are a typical organizational form; it is seen to support the goals of integrated and holistic governance (Dunleavy et al., 2006).

In the broad, society-level issues, the need for a systemic view is apparent. Here, a specific answer to a specific problem often causes the emergence of a new problem. The most fruitful model to tackle the complex bundle of problems is the simultaneous development of technologies, services, organizations and multiple network and partner relationships (Kivisaari et al., 2013). In addition, it is important to take into account the context and environment in which the objects of development are embedded. Answering context-specific issues is often a 
strength in the renewal; on the other hand, context-specificity makes it difficult to disseminate the novel solution to other contexts (Moulaert et al., 2005).

The difficulty of dissemination is linked to the fact that systemic problems cannot be identified and tackled directly, but a dialogue is needed between the practical level, on which the problems are manifested as separate troubles, and the conceptual level, on which the linkages of problems can be discovered. Several constructs have been utilized to describe this dialogue. Windrum (2008) speaks about 'conceptual innovations', referring to questioning the existing assumptions and knowledge that maintain current services, processes and organizations. Suddaby and Greenwood (2005) use the term 'theorization' to point out that linguistic devices help actors make the changes comprehensible. Maitlis and Christianson (2014) highlight sense making: positioning the change agent in the context and constructing a shared meaning of the change effort. Sense making also plays a central role in resource mobilization, which is the next challenge after the basic solution to a systemic problem has been found. Cultural-historical activity theory - which we applied above to describe human-technology systems - starts from the embedded contradictions that can be identified in all social systems. These contradictions have developed during the system's historical development and have to be revealed before a solution can be found (Engeström and Sannino, 2010).

In recent years, the social structures that promote or constrain the spread of new solutions and practices - usually including digital aspects - have aroused increasing interest. Institutional theory has been suggested as a promising framework in the analysis of this topic. Institutions can be defined as the cognitive, normative and regulative structures and activities that provide stability and meaning to social behaviour (Scott, 1995). Institutions manifest themselves in many forms; they can be formal codified laws, informal social norms, conventions (conceptual and symbolic meanings), or any other routinized rubric that provides a shortcut to cognition, communication, and judgment. In practice, they typically exist as part of more comprehensive institutional arrangements - interdependent sets of institutions (Thornton et al., 2012). The process of institutionalization is essential for both the creation and dissemination of novelties and includes the change and disruption of institutions. It is important to point out that it also includes the maintenance of some parts of older arrangements and behaviors: even innovations that represent major institutional shifts are built upon existing institutions (Wieland et al., 2016)

\section{Digitalization and systemic change}

\subsection{Cross-level Interaction of Human and Technological Resources}

Digitalization drives not only adaptive transitions and phase transitions of interaction patterns between human and technological resources but also wider societal changes in beliefs, values and governance that co-evolve with technological changes. In order to analyze digitalization in the context of interaction between human and technological resources with wider societal changes, Transition Management Theory (TMT), a basic systemic framework proposed especially for discussing societal sustainability (Kemp et al. 2009), works as a useful framework for our investigation.

As observed in the previous sections, digitalization drives simultaneous and cross-level development of organizations, technologies, services, and multiple networks and ecosystems. TMT identifies three levels in a society, namely, micro, meso and macro levels. Based on a multilevel model of social innovations TMT proposes (Kemp et al., 2009), we develop a unified model describing adaptive and phase transitions within a level as well as cross-level generationregulation processes in a society (Figure 3) (Kijima et al., 2016, Toivonen and Kijima, 2018). This model illustrates how within-level and cross-level interactions of human and technological 
resources are related and how the interactions go on dynamically. Behind the process of social change, multiple and interrelated phenomena take place at different speed and level (Rotmans and Loorbach, 2009).

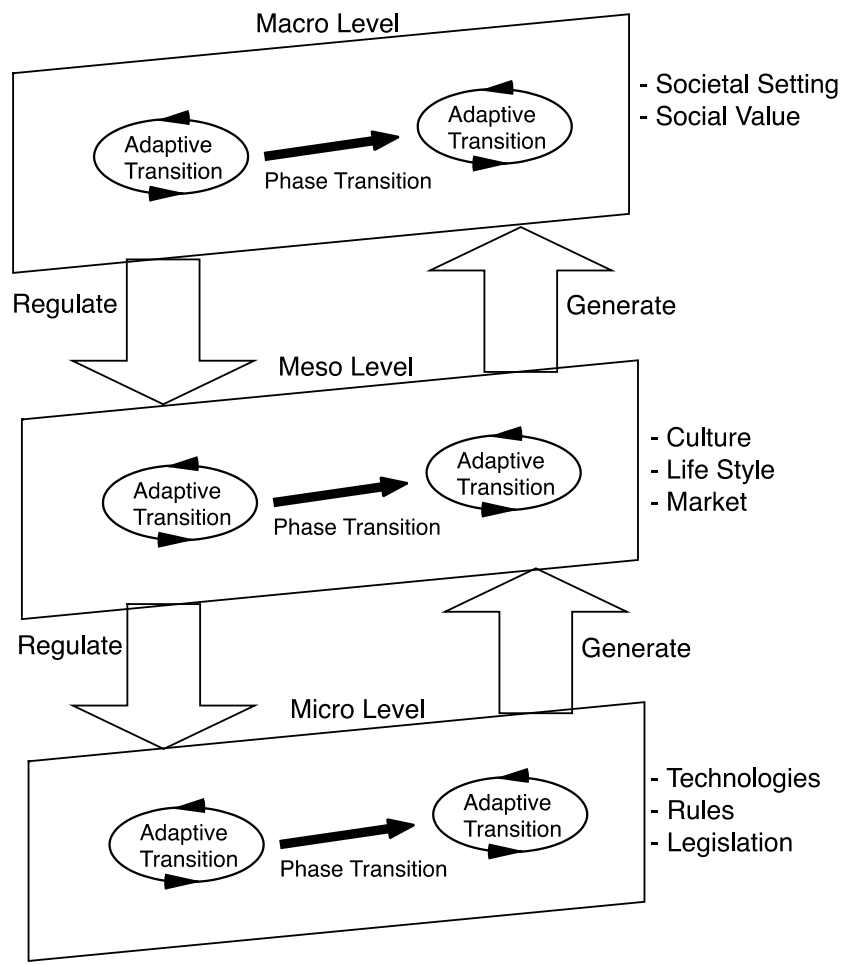

Figure 3: Interaction of Human and Technological Resources (Modified from Kijima et al., 2016, Toivonen and Kijima, 2018)

At the lowest level, which is called micro or 'niche' level by TMT, novelties are created, tested and diffused. Such novelties can be new technologies, new rules and legislation, new organizations, or even new projects, concepts or ideas. At this level, a combined process of adaptation (adaptive transitions) and a structural change from one relatively stable system to another (phase transitions) takes place (Kijima et al., 2016, Toivonen et al., 2018).

The second and middle level is the meso level at which what we call 'regime' is located. The term 'regime' refers to the dominant culture, life style, brand, market, and physical and immaterial infrastructures. These institutionalized structures give stability to the lower level and guide decision-making and individual behavior of actors. At the same time, the regime has a certain level of rigidity that normally prevents innovations from changing the structure fundamentally.

Generally faster and smaller adaptive/phase transitions at the lower level generate an impact on slower and larger adaptive/phase transitions at the higher level. At the same time, slower and larger adaptive/phase transitions at the higher level regulate faster and smaller adaptive/phase transitions at the lower level (Squazzoni, 2008). Applying these arguments, we can conclude that social needs and demands at the meso-level trigger technological innovations and phase transitions at the niche level, while, at the same time, new technologies create and lead to new life styles and social cultures. On this aspect, we can identify cross-level co- 
evolution among markets, networks, institutions, technologies, policies, individual behaviors and autonomous trends (Djalante and Djalante, 2012).

The highest level is the macro-level or 'landscape', where the overall societal setting is formed. The landscape consists of social values, belief, economic environments, and trends in a wider sense. The landscape level regulates adaptive/phase transitions at the niche and regime levels by defining the room and direction for change. At the same time, the regime and niche levels generate adaptive/phase transitions at the landscape level.

\subsection{Digital Transformation: Interactions of Human and Technological Resources}

Digital transformation or DX is a societal change in which digital technology integrates all areas of business and even brings about changes in life style. Though the definition is not rigid, digital transformation not only triggers adaptive and phase transitions but also makes crosslevel changes that continually challenge the status quo of the society as a whole.

Bottom-up or generative activities constitute an 'engine of digital transformation'. The creation and implementation of digital transformation highlights empowerment: citizens are not passive recipients, but active co-developers (Harrison et al., 2010). On the other hand, top-down or regulative activities are also necessary for the materialization and dissemination of social innovations. Decision makers and managers have to support and organize bottom-up processes in order to make ideas implementable and scalable (Høyrup, 2010).

For example, the Japanese government facing very serious aging society problem is keen to implement work style reform by inviting ex-working women and senior people back to the office employing telework systems in particular. At the same time, advancements in robotics and AI technologies gradually change people's mindset. Indeed, quite a few people now consider seriously about work-life balance from a different viewpoint and traditional seniority systems are fading out.

The framework of Hype Cycle developed by Gartner (Gartner, 2018), which tries to capture graphically the dynamics of how the development of new technologies generates expectations from business and market, aims to illustrate such cross-level generation/regulation interactions. According to it, a technology's life cycle goes through five key phases (Figure 4) and at each phase the market generates different degree of expectations to it (Gartner, 2018). The phases are as follows:

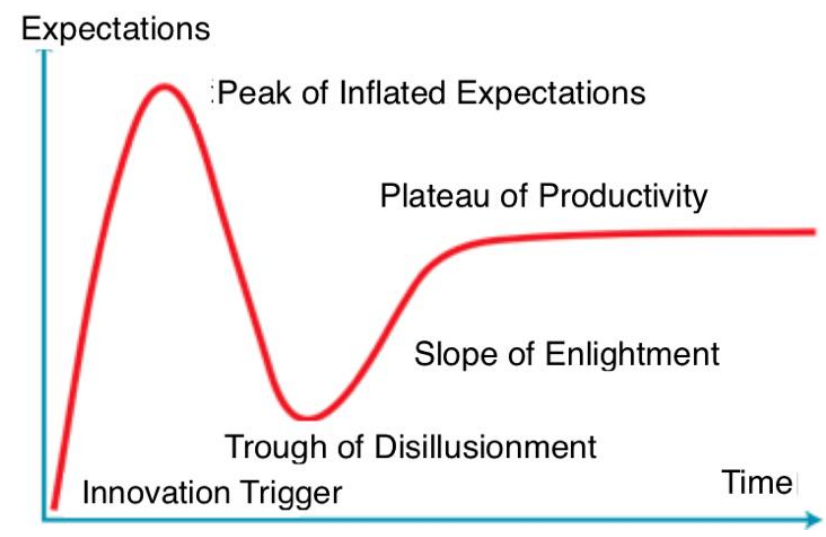

Figure 4: Hype Cycle (Gartner, 2018) 
At the 'Innovation Trigger' phase, a potential technology breakthrough kicks things off, but often non-usable products exist and commercial viability is unproven. At the 'Peak of Inflated Expectations' phase, early publicity produces a number of success stories, but often they are accompanied by scores of failures. At the 'Trough of Disillusionment' phase, producers of the technology shake out or fail. Investments continue only if the surviving providers improve their products to the satisfaction of early adopters. At the 'Slope of Enlightenment' phase, the way how the technology can benefit the enterprise becomes more widely understood. Second- and third-generation products appear from technology providers. At the 'Plateau of Productivity' phase, the mainstream adoption starts to take off and the technology's broad market applicability and relevance are clearly paying off.

The trajectory clearly shows a dynamic cyclic relationship between technology and expectations. Through the stages, technologies push societal expectations and, then, higher expectations pull new technologies. When this push-pull cycle takes a pattern of positive feedback, it leads to technological breakthrough as well as drastic societal change. These arguments suggest that 'technologies in season' is essential for such positive feedback.

\section{$5 \quad$ Concluding remarks}

In this chapter, we have analyzed the change from the early days of ICT development to the present situation, in which digitalization is an essential part of all kinds of social and economic activities and of the everyday life of citizens. Digitalization causes pervasive effects on humantechnology interaction and on sociotechnical structures. It forces us to rethink the traditional definitions of economy, wealth creation, business organizations and other institutional structures. Potential for many kinds of innovations is one of its important effects; it enables the adoption of new forms of learning and the development of various disciplines and professions.

However, the new opportunities will not be realized without human activities. In the early stages of ICT advancement, an important insight was the transfer from the analysis of mere technology to the emphasis of knowledge and learning. In the digital era, human interpretation is equally central because the relevance of knowledge is contextually defined. Further, the dependence of digitalization on human and societal activities is manifested in phenomena that require organizational and managerial solutions: networking, mobility, socio-cultural shifts, and globalization are phenomena tightly linked to digitalization.

An important message in this chapter is the systemic and dynamic nature of the interrelationships between technological and human resources. Understanding the present development requires a move of the focus from the analysis of stand-alone things and properties to the analysis of processes, interactions and resource integration. Correspondingly, impactful innovations are more and more often systemic, influencing simultaneously on technologies, services, organizations, and partner relationships.

\section{References}

Anggraeni, E., den Hartigh, E. and Zegveld, M. (2007). Business ecosystem as a perspective for studying the relations between firms and their business networks. ECCON 2007, Delft University of Technology, the Netherlands.

Antonelli, C. (1998). Localized technological change, new information technology and the knowledge-based economy: The European Evidence. Journal of Evolutionary Economics, 8 (2), 177-198. 
Bharadwaj, A., Sawy, O.A, Pavlou, P.A. and Venkatraman, N. (2013). Digital business strategy: toward a next generation of insights. MIS Quarterly, 37 (2), 471-482.

Boyd, D. and Crawford, K. (2012). Critical questions for big data: provocations for a cultural, technological and scholarly phenomenon. Information, Communication \& Society, 15 (5), 662-679.

Brettel, M., Friederichsen, N., Keller, M. and Rosenberg, M. (2014). How Virtualization, Decentralization and Network Building Change the Manufacturing Landscape: An Industry 4.0 Perspective. International Journal of Information and Communication Engineering 8 (1), 37-44.

Brynjolfsson, E. and McAfee, A. (2014): The Second Machine Age: Work, Progress, and Prosperity in a Time of Brilliant Technologies. New York: W.W. Norton \& Company.

Castells M. (1996). The Rise of Network Society. Massachusetts and Oxford: Blackwell Publishers.

Chandler, J. D. and Vargo, S.L. (2011). Contextualization and value-in-context: How context frames exchange. Marketing Theory 11(1), 35-49.

Choi, T. Y., Dooley, K. J. and Rungtusanatham, M. (2001). Supply networks and complex adaptive systems: control versus emergence. Journal of Operations Management, 19 (3), $351-366$

Craft, A. (2012). Childhood in a digital age: creative challenges for educational futures. London Review of Education, 10 (2), 173-190.

Dewey, J. (1938). Experience and education. New York: Macmillan.

Djalante, R. and Djalante, S. (2012). Transition management, new mode of governance for sustainable development. Natural Hazards, 62 (3), 1339-1341.

Dunleavy, P., Margetts, H., Bastow, S. and Tinkler, J. (2006). New Public Management Is Dead - Long Live Digital-Era Governance. Journal of Public Administration Research and Theory, 16 (3), 467-494.

Edvardsson, B., Tronvoll, B. and Gruber, T. (2011). Expanding understanding of service exchange and value co-creation: a social construction approach. Journal of Academy of Marketing Science, 39 (2), 327-339.

Engeström, Y. (1987). Learning by expanding: an activity theoretical approach to developmental research, Helsinki: Orienta-Konsultit Oy, Finland (see 2016 book edition)

Engeström, Y. (2016). Studies in Expansive Learning: Learning What Is Not Yet There. Cambridge: Cambridge University Press.

Engeström, Y. and Sannino, A. (2010). Studies of expansive learning: Foundations, findings and future challenges. Educational Research Review, 5 (1), 1-24.

Farjoun, M. (2010). Beyond dualism: Stability and change as a duality. Academy of Management Review, 35 (2), 202-225.

Floridi, L. (2015). Introduction. In Floridi, L. (Ed.), The Online Manifesto - Being Human in a Hyperconnected Era (pp. 1-6). Heidelberg, New York, Dordrecht and London: Springer Open.

Gallouj, F. (2002). Innovation in the service economy: The new wealth of nations. Cheltenham and Northampton: Edward Elgar.

Gartner, Gartner Hype Cycle, https://www.gartner.com/en/research/methodologies/gartnerhype-cycle, Nov. 4, 2018

Ghisi, F.A. and Martinelli, D.P. (2006). Systemic View of Interorganisational Relationships: An Analysis of Business Networks. Systemic Practice and Action Research, 19 (5), 461473.

Gorecky, D., Schmitt, M. and Loskyll, M. (2014). Human-machine-interaction in the industry 4.0 era, 2014 12th IEEE International Conference on Industrial Informatics (INDIN), 2730 July 2014, Porto Alegre, Brazil. 
Granovetter, M. S. (1973). The strength of weak ties. American Journal of Sociology, 78 (6), 1360-1380.doi:10.1086/225469

Gulati, R., Nohria, N. and Zaheer, A. (2000). Strategic Network. Strategic Management Journal, 21, 203-215.

Gundlach, G., T. (2006). Complexity science and antitrust? Antitrust Bulletin 51 (1), 17.

Gunther, W.A., Mehrizi, M.H.R., Huysman, M. and Feldberg, F. (2017). Debating big data: A literature review on realizing value from big data. Journal of Strategic Information Systems, 26, 191-209.

Haller, S., Karnouskos, S. and Schroth, C. (2009). The Internet of Things in an Enterprise Context. In Dominique, J., Fensel, D. and Traverso, P. (Eds.), First Future Internet Symposium - FIS 2008, LNCS 5468 (pp. 14-28), Springer Verlag.

Hargadon, A. B., and Bechky, B. A. (2006). When collections of creatives become creative collectives: A field study of problem-solving at work. Organization Science, 17 (4), 484500 .

Harrison, J., Bosse, D.A. and Phillips, R.A. (2010). Managing for stakeholders, stakeholder utility functions, and competitive advantage. Journal of Strategic Management, 31, 58-74.

Hartley, J. (2005). Innovation in Governance and Public Services: Past and Present. Public Money and Management, 25 (1), 27-34.

Hitchins, D. (2009). What are the General Principles Applicable to Systems? INCOSE Insight, $12(4), 59-63$.

Hoyrup, S. (2010). Employee-driven innovation and workplace learning: basic concepts, approaches and themes, European Review of Labour and Research, 16, 143-154.

Iansiti, M. and Levien, R. (2004). The Keystone Advantage: What the New Dynamics of Business Ecosystem Mean for Strategy, Innovation and Sustainability. Boston, MA: Harvard Business School Press.

Johnson, B. (1992). Institutional learning. In Lundvall B- $\AA$ (Ed.), National Systems of Innovation. Towards a Theory of Innovation and Interactive Learning (pp. 23-44). London and New York: Pinter.

Kash, D.E. and Rycroft, R.W. (1994). Technology Policy: Fitting Concept with Reality. Technological Forecasting and Social Change, 47 (1), 35-48.

Kemp, R., Loorbach, D. and Rotmans, J. (2009). Transition management as a model for managing processes of co-evolution towards sustainable development. International Journal of Sustainable Development \& World Ecology, 14 (1), 78-91.

Kijima, K., Toivonen, M. and Ruutu, S. (2016): Service Ecosystems Innovation in Systemic Perspective: Transitions and Co-evolutions. In Toivonen, M. (Ed.), Service Innovation (pp. 51-68). Series of Translational Systems Sciences, Tokyo: Springer.

Kivisaari, S., Saari, E., Lehto, J., Kokkinen, L. and Saranummi, N. (2013). System innovation in the making: hybrid actors and the challenge of up-scaling. Technology Analysis \& Strategic Management, 25 (2), 187-201.

Klir, G. (2001). Facets of Systems Science (Second Edition), New York: Kluwer Academic/Plenum Publishers.

Livingstone, S., Haddon, L., Görzig, A. and Ólafsson, K. (2011.) Risks and safety on the Internet: the perspective of European children. EU Kids Online Network, Deliverable D4, London, UK. http://eprints.lse.ac.uk/33731/, retrieved $18^{\text {th }}$ September 2018.

Lundvall, B- $\AA$. (1992). Introduction. In Lundvall B- $\AA$ (Ed.), National Systems of Innovation. Towards a Theory of Innovation and Interactive Learning (pp. 1-19). London and New York: Pinter.

Lundvall, B-Å (1999). Technology policy in the learning economy. In Archibugi, D., Howells, J. and Michie, J. (Eds.), Innovation Policy in a Global Economy (pp. 19-34). Cambridge: Cambridge University Press. 
Lundvall, B-Å. and Johnson B. (1994). The Learning Economy. Journal of Industry Studies, 1 (2), 23-42.

Lupton, D. (2013). The digitally engaged patient: Self-monitoring and self-care in the digital health era. Social Theory \& Health, 11 (3), 256-270.

Lusch, R., Vargo, S. L. and Tanniru, M. (2010). Service, value networks and learning. Journal of the Academy of Marketing Science, 38 (1), 19-31.

McAfee, A. and Brynjolfsson, E. (2012). Big data: the management revolution. Harvard Business Review, October, 1-9.

Maitlis, S. and Christianson, M. (2014). Sensemaking in Organizations: Taking Stock and Moving Forward. The Academy of Management Annals, 8 (1), 57-125.

Mele., C. and Russo-Spena, T. (2018). A Dynamic Alternative to Linear Views On innovation: Combining Innovating in Practice with Expansive Learning. In Vargo, S. and Lusch, R. (Eds.), The SAGE Handbook of Service-Dominant logic (pp. 531-560), London, Thousand Oaks, New Delhi and Singapore: SAGE Publications Ltd.

Mokyr, J., Vickers, C. and Ziebarth, N.L. (2015). The History of Technological Anxiety and the Future of Economic Growth: Is This Time Different? Journal of Economic Perspectives 29 (3), 31-50.

Moulaert F.F., Martinelli, F., Swyngedouw, E and Gonzalez, S. (2005). Towards Alternative model(s) of Local Innovation. Urban Studies, 42 (11), 1969-1990.

O’Connor, S., Hanlon, P., O’Donnell, C., Garcia, S., Glanville, J. and Mair, F.S. (2016). Understanding factors affecting patient and public engagement and recruitment to digital health interventions: a systematic review of qualitative studies. BMC Medical Informatics and Decision Making, https://doi.org/10.1186/s12911-016-0359-3

Pedersen, J., Kocsis, D., Tripathi, A., Tarrell, A., Weerakoon, A., Tahmasbi, N., Xiong, J., Deng, W., Oh, O. and De Vreede, G.J. (2013): Conceptual foundations of crowdsourcing: A review of IS research, Proceedings of the 46th Hawaii International Conference on System Sciences, 2013, Hawaii, https://ieeexplore.ieee.org/document/6479904/, retrieved $22^{\text {nd }}$ September 2018.

Ragnedda, M. and Muschert, G.W. (2013). Introduction. In Ragnedda, M. and Muschert, G.W. (Eds.), The Digital Divide: The Internet and Social Inequality in International Perspective (pp. 1-14). New York: Routledge.

Rotmans, J. and Loorbach, D., (2009). Complexity and Transition Management. Journal of Industrial Ecology, 13 (2), 184-196.

Scott, W.R. (1995): Institutions and organizations. $1^{\text {st }}$ ed. Thousand Oaks, California: Sage Publications.

Sharples, M., Taylor, J., and Vavoula, G. (2007). A theory of learning for the mobile age. In Andrews, R. and Haythornthwaite, C. (Eds.), The SAGE handbook of e-learning research (pp. 221-247). London: SAGE.

Siemens, (2014). Connectivism: A Learning Theory for the Digital Age. e-Learning Library, http://er.dut.ac.za/handle/123456789/69, retrieved 17 ${ }^{\text {th }}$ September 2018.

Simon, H.A. (1962). The Architecture of Complexity. Proceedings of the American Philosophical Society, 106 (6) (Dec. 12, 1962), 467-482.

Simon, H. A. (1996): The Sciences of the Artificial, 3rd ed. Cambridge, MA: MIT Press.

Soria-Comas, J. and Domingo-Ferrer, J. (2016). Big Data Privacy: Challenges to Privacy Principles and Models. Data Science and Engineering, 1 (1), 21-28.

Squazzoni, F., (2008). The Micro-Macro Link in Social Simulation. Sociologica, II (1), doi: $10.2383 / 26578$

Stein, V. (2015). Human Resources Development in Times of Digitalization: A Dynamization Agenda. Arbeitspapier Nr. 006-2015, www.uni-siegen.de, retrieved $16^{\text {th }}$ September 2018.

Suddaby, R. and Greenwood, R. (2005). Rhetorical Strategies of Legitimacy. Administrative 
Science Quarterly, 50, 35-67.

Thornton, P.H., Ocasio, W. and Lounsbury, M. (2012). The Institutional Logics Perspective: A New Approach to Culture, Structure and Process. Oxford: Oxford University Press.

Toivonen, M. and Kijima, K., (2018). The Need for a New Innovation Paradigm and the Contribution of Service-Dominant Logic. In Vargo, S. and Lusch, R. (Eds.), The SAGE Handbook of Service-Dominant logic (pp. 487-507), London, Thousand Oaks, New Delhi and Singapore: SAGE Publications Ltd.

Tuomi, I. (2002). Networks of Innovation. Change and Meaning in the Age of the Internet. Oxford: Oxford University Press.

Tyner, K. (2014). Literacy in a Digital World: Teaching and Learning in the Age of Information. New York: Routledge.

van Dijk, J. (2013): A theory of Digital Divide. In Ragnedda, M. and Muschert, G.W. (Eds.), The Digital Divide: The Internet and social inequality in international perspective (pp. 2952). New York: Routledge.

Vargo, S. and Lusch, R. (2004). Evolving to a New Dominant Logic for Marketing. Journal of Marketing, 68 (1), 1-17.

Vargo, S, and Lusch, R. (2011). It's all B2B... and beyond: Toward a systems perspective of the market, Industrial marketing Management, 40, 181-187.

Vargo, S. and Lusch, R. (Eds.) (2018): The SAGE Handbook of Service-Dominant Logic. London, Thousand Oaks, New Delhi and Singapore: SAGE Publications Ltd.

Wieland, H., Vargo, S., \& Akaka, M.A. (2016). Zooming Out and Zooming In: Service Ecosystems as Venues for Collaborative Innovation. In Toivonen, M. (Ed.), Service innovation - novel ways of creating value in actor systems (pp. 35-50). Tokyo: Springer.

Windrum, P. (2008). Introduction. In Windrum, P. and Koch, P. (Eds.), Innovation in Public Sector Services: Entrepreneurship, Creativity and Management (pp. 3-20). Cheltenham and Northampton: Edward Elgar. 